\title{
NUTRACEUTICAL POTENTIAL OF VERMICELLI PREPARED BY GLUTEN-FREE COMPOSITE FLOUR
}

\author{
SRISHTI AGARWAL, EKTA SINGH CHAUHAN* \\ Department of Food Science and Nutrition, Banasthali Vidyapith, Rajasthan, India 304022 \\ Email: ekta34.ers@gmail.com \\ Received: 11 Sep 2021, Revised and Accepted: 14 Nov 2021
}

\begin{abstract}
Objective: Nutritional, phytochemical and antioxidant properties of all ratios of gluten free composite flour-based Vermicelli was evaluated in this study. The blend of proso millet flour (PF), adzuki bean flour (AF) and basil seeds flour (BF) was used in composite flour.

Methods: The variations of three composite flours were prepared as, A being (PF: AF: $B F=50: 45: 5), B$ being (PF: AF: $B F=60: 35: 5)$ and C being (PF: AF: $B F=70: 25: 5)$, respectively. The macronutrients like moisture, ash, fat, fiber, protein and carbohydrate were assessed in this study. Minerals such as calcium, iron, phosphorus and zinc were analyzed in micronutrients.

Results: The result of macronutrient and micronutrient of a ratio were moisture (5.2 \pm 0.1$)$, ash (2.1 \pm 0.2$)$, protein (13.0 \pm 0.0$)$, fat (1.6 \pm 0.0$)$, fiber $(3.0 \pm 0.0)$ and carbohydrate $(60.0 \pm 0.2 \mathrm{~g} / 100 \mathrm{~g})$ respectively. Calcium $(150.0 \pm 0.3)$, iron (3.5 \pm 0.1$)$, zinc $(2.0 \pm 0.3)$ and phosphorus $(250.6 \pm 0.6$ $\mathrm{mg} / 100 \mathrm{~g}$ ) were also there in gluten-free Pasta. The current study revealed that various macro and micronutrients were present in gluten-free Vermicelli. In the prepared products, flavonoids, saponins, tannin, glycocides, alkaloids and steroids are the few phytochemicals present. The study results also show that gluten-free Vermicelli has good antioxidant activity. In the A ratio, overall, all nutrients are found. It was found by the sensory evaluation Vermicelli on a 9 point hedonic scale that A ratio was more acceptable than the $\mathrm{B}$ and $\mathrm{C}$ ratio.
\end{abstract}

Conclusion: Therefore, it can be useful for celiac diseases as well as patients suffering from diseases like hypertension, anemia and diabetes.

Keywords: Composite flour, Chemical composition, Gluten-free Vermicelli, Antioxidant activity, Nutraceutical

(C) 2022 The Authors. Published by Innovare Academic Sciences Pvt Ltd. This is an open access article under the CC BY license (https://creativecommons.org/licenses/by/4.0/) DOI: https://dx.doi.org/10.22159/ijcpr.2022v14i1.44116 Journal homepage: https://innovareacademics.in/journals/index.php/ijcpr

\section{INTRODUCTION}

Worldwide, genetically vulnerable individuals are affected by lifetime autoimmune disease in the small intestine, known as celiac disease or gluten intolerance. It is one of the most widespread diseases prevailing these days. This disease can be caused by both environmental (gluten) and genetic (HLA and nonHLA genes) factors [1]. The main problem occurs in this disease is the damage of the villi of the small intestine as the result absorption of nutrients from food is also hindered. A hundred percent gluten-free diet is the only existing treatment for celiac today as there is no pharmaceutical cure for celiac disease. So, it is essential to build up gluten-free foods that are consumeracceptable. There is an increased require for gluten-free products like bakery and extruded items all over the world because of the larger awareness of celiac disease [2]. So, basically, composite flour is used to involve gluten-free products in the market. Composite flour is a combination of wheat and non-wheat flours. These non-wheat flours can be made out of cereals, roots, tubers, legumes, or other raw materials. Traditional products like chakli or new products like muffins can be made from this composite flour. Composite flours have been broadly used in the preparation of baked and other kinds of products due to their organoleptic acceptability and functional roles of flour components [3].

Vermicelli is a well-liked instant food product made up from wheat flour which comes under the type of extruded product. It is a snack food item liked by people from all walks of life, irrespective of age. Better awareness about health preference for instant food items like vermicelli has become very popular with changing lifestyle. However, gluten-free vermicelli is significant for people who have celiac disease and also for people who are interested in gluten-free products. Proso millet, adzuki beans and basil seeds are carefully selected for the present study. The nutritional or functional attribute of the product developed is determined by it. Proso millet contains all macro and micronutrients in substantial amounts as well as contains all essential amino acids. Adzuki beans pass on many functional properties such as water and oil absorption capacity in the composite flour [4]. Basil seed flour was found to be very useful in terms of flavor, crispiness and texture [5]. Thus, as a result, composite flour-based baked products will have a good physical appearance and texture.

Thus, the main objective of the research is to evaluate prepared vermicilli with composite flour for its proximate composition, phytochemical and antioxidant activity that can further direct research towards its applications for gluten-free food product development in the market.

\section{MATERIALS AND METHODS}

\section{Collection of plant material}

The seeds were obtained from the local market of Delhi, India. The seeds were dried at $100{ }^{\circ} \mathrm{C}$ in an oven for half an hour. The dried sample of seeds was milled with a mechanical blender and stored in air-tight containers in a refrigerator for further analysis.

\section{Determination of proximate composition}

Cupcakes flour was taken in a clean, dry and weighed crucible. It was oven-dried later on at $110{ }^{\circ} \mathrm{C}$. It was weighed repeatedly until a constant weight was acquired. The crucible was cool down in desiccators every time before weighing. Proximate analysis included the estimation of moisture ash, fat, protein, crude fiber and carbohydrate of seeds. Total ash was estimated by weighing the furnace in incinerated residue at $550{ }^{\circ} \mathrm{C}$ for $12 \mathrm{~h}$. Protein was analyzed by using micro-Kjeldahl distillation method. Carbohydrate content was determined by the difference method.

\section{Determination of minerals}

Chemical estimations were carried out for determining calcium (Ca), iron $(\mathrm{Fe})$ and zinc $(\mathrm{Zn})$. The estimation of $\mathrm{Ca}, \mathrm{Fe}, \mathrm{P}$, and $\mathrm{Zn}$ was done by using atomic absorption spectrophotometer (AAS) (model VGP 210, Buck Scientific, USA). 


\section{Phytochemical and antioxidant screening}

The cupcake flour was screened for phytochemicals (flavonoids, saponins, tannin, glycocides and steroids) according to the procedure as described by (Tiwari et al., 2011; Boakye et al., 2015). Antioxidant analysis was done on DPPH (diphenylpicryhydrazyl) activity, FRAP (ferric reducing ability of plasma) and nitric oxide scavenging activity [6-10].

\section{Results and discussion}

\section{Macronutrients}

Proso millet flour, adzuki beans flour and basil seeds flour were used to prepare gluten-free composite flour. Moisture, ash, protein, fat, fiber and carbohydrate content were then evaluated for glutenfree vermicelli. The chemical composition of vermicelli with different ratios is presented in table 1 . The variant $\mathrm{C}$ has the highest content of composite flour after standard. The reason for the same is that Proso millet has a high amount of moisture when compared with adzuki beans and basil seeds. Mandge et al., (2014) [11] conducted the same study on adzuki beans in which moisture content was found to be $4.2 \mathrm{~g} / 100 \mathrm{~g}$. Proso millet contains less amount of moisture which is beneficial for increasing the shelf life of millet in comparison to other gluten-free cereals like maize, brown rice and sorghum [12]. The result of the analysis shows that variant $\mathrm{C}$ have higher amount ash, fat, carbohydrate and fiber as compared to all variants. It is due to the highest ratio of Proso millet was present in variant C. Similar results were seen in a study conducted by Saturni et al., (2010) in which Proso millet contain good amount of these nutrients as a comparison to other gluten free cereals. Among all the ratios, Protein was found higher invariant A.

Table 1: Proximate composition of gluten free vermicelli

\begin{tabular}{|c|c|c|c|c|c|c|}
\hline Variants & Moisture & Ash & Protein & Fat & Fiber & Carbohydrate \\
\hline Standard & $5.0 \pm 0.0$ & $1.9 \pm 0.1$ & $8.0 \pm 0.2$ & $0.5 \pm 0.1$ & $1.0 \pm 0.0$ & $70.0 \pm 0.3$ \\
\hline Variant A & $5.2 \pm 0.1$ & $2.1 \pm 0.2$ & $13.0 \pm 0.0$ & $1.6 \pm 0.0$ & $3.0 \pm 0.0$ & $60.0 \pm 0.2$ \\
\hline Variant B & $5.6 \pm 0.0$ & $2.4 \pm 0.3$ & $12.5 \pm 0.1$ & $1.8 \pm 0.1$ & $2.5 \pm 0.3$ & $65.2 \pm 0.1$ \\
\hline Variant C & $6.1 \pm 0.2$ & $3.7 \pm 0.0$ & $12.0 \pm 0.3$ & $2.0 \pm 0.0$ & $2.2 \pm 0.1$ & $67.5 \pm 0.1$ \\
\hline \multicolumn{4}{|c|}{ Standard $=100 \%$ Wheat flour } & \multirow{2}{*}{\multicolumn{3}{|c|}{$\begin{array}{l}A=50 \% \text { Proso millets }+45 \% \text { Adzuki beans }+5 \% \text { basil seeds } \\
C=70 \% \text { Proso millets }+25 \% \text { Adzuki beans }+10 \% \text { Basil seeds }\end{array}$}} \\
\hline \multicolumn{4}{|c|}{$\mathrm{B}=60 \%$ Proso millets $+35 \%$ Adzuki beans $+10 \%$ Basil seeds } & & & \\
\hline
\end{tabular}

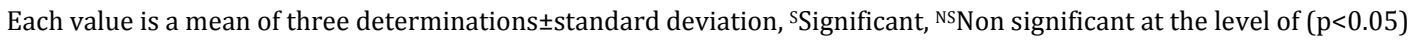

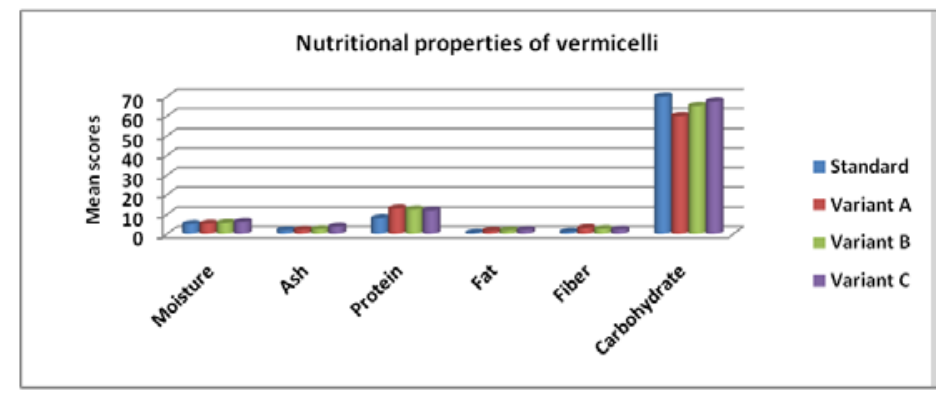

Fig. 1: Nutritional properties of vermicelli

\section{Micronutrients}

\section{Minerals}

The mineral content of all the nutrients was found to be highest in variant $\mathrm{C}$ except calcium, as shown in table 2 . Adzuki beans are the richest source of calcium in comparison to Proso millet as calcium content $(150.0 \pm 0.3)$ was higher invariant A $[13,14]$. Similar results were in a study conducted by [15], wherein high amount of iron, zinc and phosphorus was present in Proso millet when compared to Adzuki beans.

Table 2: Mineral composition of gluten free vermicelli

\begin{tabular}{llll}
\hline Variants & Calcium & Iron & Zinc \\
\hline Standard & $50.2 \pm 0.0$ & $1.4 \pm 0.2$ & $1.0 \pm 0.0$ \\
A & $150.0 \pm 0.3$ & $3.5 \pm 0.1$ & $2.0 \pm 0.3$ \\
B & $132.5 \pm 0.0$ & $3.7 \pm 0.5$ & $2.6 \pm 0.6$ \\
C & $128.9 \pm 0.1$ & $3.9 \pm 0.0$ & $2.8 \pm 0.2$ \\
Standard = 100\% Wheat flour & & $\mathrm{A}=50 \%$ Proso millets+45\% Adzuki beans+5\% Basil seeds \\
B =60\% Proso millets+35\% Adzuki beans+5\% Basil seeds & & $\mathrm{C}=70 \%$ Proso millets+25\% Adzuki beans+5\% Basil seeds \\
\hline
\end{tabular}

Each value is a mean of three determinations \pm standard deviation, sSignificant, NSNon significant at the level of $(p<0.05)$

\section{Phytochemicals}

Phytochemicals are mainly produced by plants and are found in foods like whole grain, herbs, fruits and vegetables, which give them disease protective properties against various ailments, such as cancer and heart diseases. Dietary intake of phytochemicals has various health benefits. It is useful in reducing the damage caused by oxidative degeneration [16]. The qualitative phytochemical analysis of the aqueous extracts of gluten-free vermicelli flour showed positive results for the presence of flavonoids, saponin, tannin, glycosides and steroid, which are shown in table 3 . According to previous studies, tannin, saponin and alkaloids have been linked with antibacterial and anti-viral activity. In modern clinical studies, steroids play their role as anti-inflammatory and analgesic agents. Flavonoids are phenolic substances which show biological activities such as vasodilating actions. Phenolic compounds are particularly known for their antioxidant potential. This is because of their ability to decrease and scavenge free radicals and preventing oxidative cell damage and as a result combating cancer [17]. 


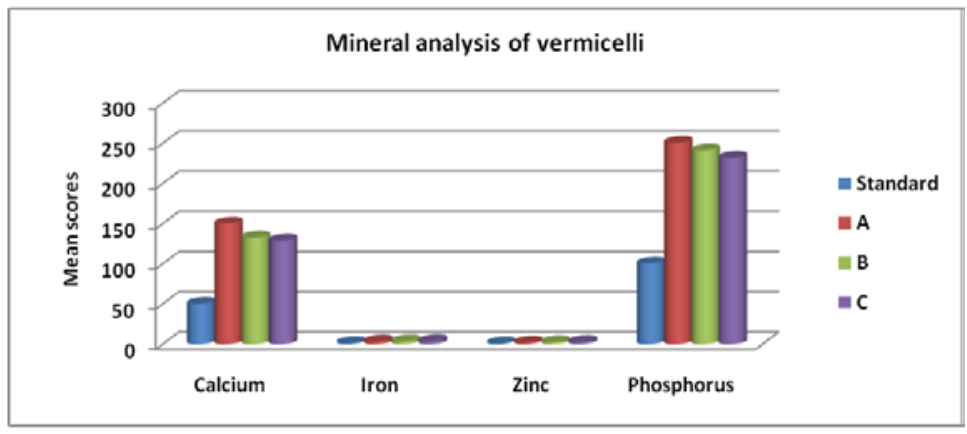

Fig. 2: Mineral analysis of vermicelli

Table 3: Phytochemical screening of gluten-free vermicelli

\begin{tabular}{lllll}
\hline Phytochemical & Standard & A & B & C \\
\hline Flavonoids & + & + & + & + \\
Saponin & + & + & + & + \\
Tannin & + & + & + & + \\
Glycosides & + & + & + & + \\
Steroids & + & + & + \\
\hline
\end{tabular}

\section{FRAP}

Table 5 shows ferric acid-reducing power for gluten-free vermicilli. The results revealed that $\mathrm{C}$ ratio exhibited the highest activity i. e
$(15.772 \mu \mathrm{g} / \mathrm{g})$ when compared with other respective variants and standard. On the contrary, reported by Chlopicka et al., (2012) that other pseudo-cereal (buckwheat, amaranth and quinoa) had highest ferric acid-reducing power.

Table 5: Ferric acid-reducing power activity of gluten-free vermicelli

\begin{tabular}{llll|}
\hline Standard & Variant A & Variant B \\
\hline $10.19 \mu \mathrm{g} / \mathrm{g}$ & $13.24 \mu \mathrm{g} / \mathrm{g}$ & $14.64 \mu \mathrm{g} / \mathrm{g}$ \\
\hline $\mathrm{n}$ & & \\
\hline
\end{tabular}

Fig. 5: FRAP activity of gluten free vermicelli

Table 4: Sensory quality attributes of gluten free vermicelli

\begin{tabular}{llllll}
\hline Variants & Color & Appearance & Flavor & Texture & Taste \\
\hline Standard & $8.8 \pm 0.5$ & $8.4 \pm 0.4$ & $8.4 \pm 0.4$ & $8.6 \pm 0.6$ & $8.4 \pm 0.6$ \\
A & $8.5 \pm 0.4$ & $8.2 \pm 0.7$ & $8.1 \pm 0.1$ & $8.3 \pm 0.5$ & $8.2 \pm 0.4$ \\
B & $7.9 \pm 0.7$ & $8.5 \pm 0.3$ & $8.1 \pm 0.3$ & $8.1 \pm 0.5$ & $8.1 \pm 0.4$ \\
C & $7.8 \pm 0.4$ & $7.7 \pm 0.6$ & $7.3 \pm 0.4$ & $7.5 \pm 0.3$ & $8.2 \pm 0.2$ \\
\hline
\end{tabular}

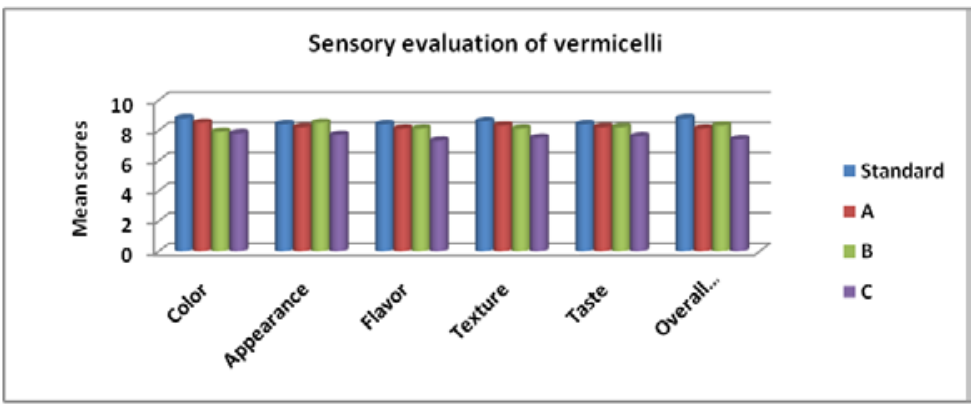

Fig. 3: Sensory evaluation of vermicelli 


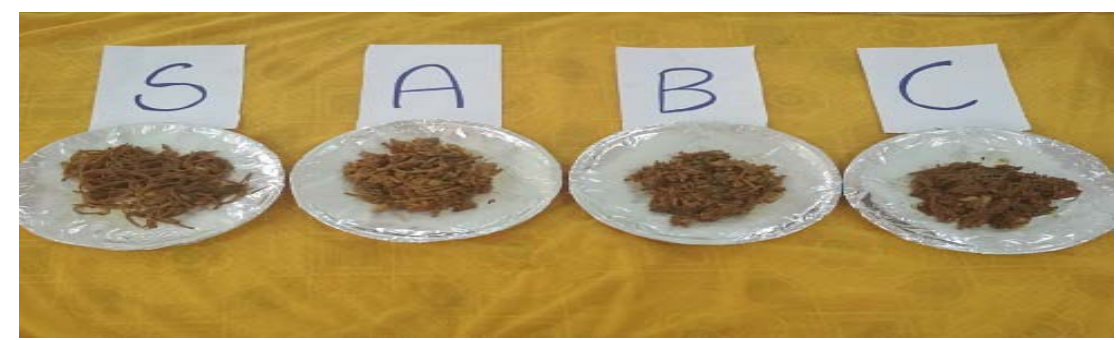

Fig. 4: Image depicting physical appearance of gluten free Vermicelli

\section{Sensory evaluation}

The mean sensory scores for colour, appearance, flavor, texture, taste and overall acceptability are presented in table 4 . Control was the most acceptable for all the attributes. Variant B was the most acceptable for all the attributes among the all three variants of composite flour-based vermicelli.

\section{CONCLUSION}

From this study, it can conclude that gluten-free cupcakes prepared by using composite flour is beneficial for celiac patients, and the selected variants also fulfill the nutritional requirement in comparison to the one made up of wheat flour. The combination of millet, bean, and seeds makes these cupcakes good in taste, texture, enhance the overall acceptability and acceptable by the panelists.

\section{ACKNOWLEDGEMENT}

The authors would like to gratefully acknowledge the Department of Food Science and Nutrition, Banasthali Vidyapith for providing necessary facilities.

\section{FUNDING}

Nil

\section{AUTHORS CONTRIBUTIONS}

All the authors have contributed equally.

\section{CONFLICT OF INTERESTS}

The authors declare that there is no conflict of interest regarding the publication of this paper.

\section{REFERENCES}

1. Gujral N, Freeman HJ, Thomson AB. Celiac disease: prevalence, diagnosis, pathogenesis and treatment. World J Gastroenterol. 2012;18(42):6036-59. doi: 10.3748/wjg.v18.i42.6036, PMID 23155333.

2. Kaur K, Singh G, Singh N. Development and evaluation of gluten-free muffins utilizing green banana flour. Bioved. 2017;28(2):359-65.

3. Menon L, Majumdar SD, Ravi U. Development and analysis of composite flour bread. J Food Sci Technol. 2015;52(7):4156-65. doi: 10.1007/s13197-014-1466-8, PMID 26139880.

4. Singh M, Byars JA, Liu SX. Navy bean flour particle size and protein content affect cake baking and batter quality (1). J Food Sci. 2015;80(6):E1229-34. doi: 10.1111/1750-3841.12869. PMID 25922214.

5. Wani SH, Gull A, Allaie F, Safapuri TA. Effects of incorporation of whey protein concentrate on physicochemical, texture, and microbial evaluation of developed cookies. Cogent Food Agric. 2015;1(1):1-9. doi: 10.1080/23311932.2015.1092406.

6. Tiwari P, Kumar B, Kaur M, Kaur G, Kaur M, Kaur G, Kaur H. Phytochemical screening and extraction: a review. Int PharmSci. 2011;1(1):98-106.

7. Boakye AA, Wireko Manu FD, Agbenorhevi JK, Oduro I. Antioxidant activity, total phenols and phytochemical constituents of four underutilized tropical fruits. Int Food Res J. 2015;22(1):262-8.

8. Brand Williams W, Cuvelier ME, Berset C. Use of a free radical method to evaluate antioxidant activity. LWT- Food Science and Technology. 1995;28(1):25-30. doi: 10.1016/S00236438(95)80008-5.

9. Benzie IFE, Strain JJ. The ferric reducing ability of plasma (FRAP) as a measure of "antioxidant power": the FRAP assay. Anal Biochem. 1996;239(1):70-6. doi: 10.1006/ abio.1996.0292, PMID 8660627.

10. Kumar S, Kumar D, Manjusha, Saroha K, Singh N, Vashishta B. Antioxidant and free radical scavenging potential of Citrullus colocynthis (L.) Schrad. methanolic fruit extract. Acta Pharm. 2008;58(2):215-20. doi: 10.2478/v10007-008-0008-1. PMID 18515231.

11. Mandge HM, Sharma S, Dar BN. Instant multigrain porridge: effect of cooking treatment on physicochemical and functional properties. J Food Sci Technol. 2014;51(1):97-103. doi: 10.1007/s13197-011-0461-6, PMID 24426053.

12. Gebremariam MM, Zarnkow M, Becker T. Teff (Eragrostis tef) as a raw material for malting, brewing and manufacturing of gluten-free foods and beverages: a review. J Food Sci Technol. 2014;51(11):2881-95. doi: 10.1007/s13197-012-0745-5, PMID 26396284.

13. Saturni L, Ferretti G, Bacchetti T. The gluten-free diet: safety and nutritional quality [review]. Nutrients. 2010;2(1):16-34. doi: 10.3390/nu20100016, PMID 22253989.

14. Devi KV, Pai RS. Antiretrovirals: need for an effective drug delivery. Indian J Pharm Sci. 2006;68(1):1-6. doi: 10.4103/0250-474X.22955.

15. Parida S, Jana S, Behera S, Nayak B. Quality assessment of gluten-free muffins from buckwheat flour and rice bran. J Pharmacogn Phytochem. 2018;1:1825-30

16. Prakash D, Gupta C, Sharma G. Importance of phytochemicals in nutraceuticals. J Chin Med Res Dev. 2012;1(3):70-8.

17. Saio V, Syiem D. Phytochemical analysis of some traditionally used medicinal plants of north-east India. J Sci Environ Today. 2015;1:6-13.

18. Chlopicka J, Pasko P, Gorinstein S, Jedryas A, Zagrodzki P. Total phenolic and total flavonoid content, antioxidant activity and sensory evaluation of pseudocereal breads. LWT- Food Science and Technology. 2012;46(2):548-55. doi: 10.1016/ j.lwt.2011.11.009. 